\title{
Nitric oxide delivery during cardiopulmonary bypass reduces postoperative morbidity in children-a randomized trial
}

\author{
Paul A. Checchia, MD, FCCM, FACC, Ronald A. Bronicki, MD, Jared T. Muenzer, MD, David Dixon, PhD, \\ Steve Raithel, BS, CCP, Sanjiv K. Gandhi, MD, and Charles B. Huddleston, MD
}

\begin{abstract}
Objective: Cardiac surgery requiring cardiopulmonary bypass and cardioplegic arrest leads to myocardial ischemic and reperfusion injury. Gaseous nitric oxide has been demonstrated to have a myocardial protective effect following ischemia-reperfusion. We hypothesized that gaseous nitric oxide administered during cardiopulmonary bypass would have similar beneficial effects.
\end{abstract}

\begin{abstract}
Methods: In a prospective, randomized, blinded, placebo-controlled study, children undergoing repair of tetralogy of Fallot received either 20 ppm of gaseous nitric oxide or placebo delivered to the membrane oxygenator during cardiopulmonary bypass.

Results: A total of 16 children were randomized into 2 equal groups once their parents or guardians had given written informed consent. No differences were found in age, crossclamp time, cardiopulmonary bypass time, or methemoglobin between the 2 groups. The group receiving gaseous nitric oxide had a significantly shortened duration of mechanical ventilation $(8.4 \pm 7.6$ vs $16.3 \pm 6.5$ hours; $P<.05)$ and intensive care unit length of stay $(53.8 \pm 19.7$ vs $79.4 \pm 37.7$ hours; $P<.05)$ compared with the placebo group. The patients had significantly lower troponin levels at 12,24, and 48 hours $(P<.05)$ and lower B-type natriuretic peptide levels at 12 and 24 hours $(P<.05)$. A trend was found toward a less positive fluid balance, with significantly less diuretic usage. The study patients had a greater mean hemoglobin at 48 hours, despite the absence of differences in chest tube output, packed red blood cell transfusion, platelet counts or transfusion requirements, fresh frozen plasma transfusion, or prothrombin time/partial thromboplastin time in the first 48 hours.
\end{abstract}

Conclusions: The delivery of gaseous nitric oxide to the cardiopulmonary bypass circuit for children undergoing cardiac surgery results in myocardial protection, improved fluid balance, and an improved postoperative intensive care unit course. (J Thorac Cardiovasc Surg 2013;146:530-6)

Cardiac surgery requiring cardiopulmonary bypass (CPB) and cardioplegic arrest leads to myocardial ischemic and reperfusion injury. This combination of insults leads to myocardial necrosis in as many as $40 \%$ of cardiac surgeries. ${ }^{1}$ These phenomena cause cardiac, vascular, and pulmonary dysfunction. ${ }^{2}$ Central to the pathophysiology of reperfusion injury is a robust local inflammatory response that contributes to the CPB-induced systemic inflammatory response. The responsible cellular and molecular mechanisms are not completely understood but include complement activation, cytokine release, endothelial injury, and apoptosis. ${ }^{3}$

From the Cardiovascular Intensive Care Unit, Department of Pediatrics, Texas Children's Hospital, Baylor College of Medicine, Houston, Tex; and the Departments of Surgery and Pediatrics, Washington University School of Medicine, St Louis, Mo.

This study was supported by a research grant from Ikaria, Inc (to P.A.C.) and National Institutes of Health/National Institute of General Medical Sciences grant K08GM084143-01 (to J.T.M.).

Disclosures: Authors have nothing to disclose with regard to commercial support.

Received for publication April 5, 2012; revisions received Aug 10, 2012; accepted for publication Sept 13, 2012; available ahead of print Dec 10, 2012.

Address for reprints: Paul A. Checchia, MD, FCCM, FACC, Cardiovascular Intensive Care Unit, Department of Pediatrics, Texas Children's Hospital, Baylor College of Medicine, 6621 Fannin, WT6-006, Houston, TX 77030 (E-mail: checchia@ bcm. edu).

$0022-5223 / \$ 36.00$

Copyright (c) 2013 by The American Association for Thoracic Surgery

http://dx.doi.org/10.1016/j.jtcvs.2012.09.100
One major component of this process, and the focus of the present investigation, is the nitric oxide (NO) pathway. NO can play several protective roles in the inflammatory response, ischemia/reperfusion injury, and apoptosis. ${ }^{4}$ For example, gaseous $\mathrm{NO}$ ( $\mathrm{gNO}$ ) has been demonstrated to have a myocardial protective effect, primarily by ameliorating reperfusion injury. ${ }^{5}$ Additionally, alterations in NO generation appear to underpin the interrelationship of endothelial function and inflammation. ${ }^{6}$ Given this evidence, administration of NO might prove effective in decreasing the incidence of morbidity after cardiac surgery.

We hypothesized that myocardial ischemia/reperfusion injury might be modulated through the innovative delivery of supplemental gNO during $\mathrm{CPB}$ and thus improve the postoperative course. Our premise was that gNO delivered to the circuit allows immediate availability of $\mathrm{NO}$ at the moment of reperfusion and has effects distal to the entry site. Through the present randomized, blinded, placebo-controlled trial, we aimed to determine the effects of supplemental gNO on ischemia/reperfusion injury, the inflammatory response, and the resultant end-organ injury after $\mathrm{CPB}$.

\section{METHODS}

Children undergoing complete repair of tetralogy of Fallot from July 2007 to October 2010 were eligible for participation. The trial was 


$$
\begin{aligned}
& \text { Abbreviations and Acronyms } \\
& \text { BNP }=\text { B-type natriuretic peptide } \\
& \text { CICU }=\text { cardiac intensive care unit } \\
& \text { CPB }=\text { cardiopulmonary bypass } \\
& \text { cTnI }=\text { cardiac troponin I } \\
& \text { gNO }=\text { gaseous nitric oxide } \\
& \text { IL }=\text { interleukin } \\
& \text { NO }=\text { nitric oxide }
\end{aligned}
$$

registered with ClinicalTrials.gov (NCT00585013), and the Washington University School of Medicine institutional review board approved the study. The parents or guardians of all patients approved the present study. The patients were randomized into 1 of 2 groups: group 1, intraoperative administration of $20 \mathrm{ppm}$ of $\mathrm{gNO}$ to the oxygenator of the CPB circuit; or group 2, placebo gas treatment.

Other than failure to obtain informed consent, the patients potentially eligible for enrollment were excluded for any of the following reasons: (1) signs of persistently elevated pulmonary vascular resistance preoperatively; (2) cardiac arrest 1 week before surgery; (3) previous surgical procedure that required the use of $\mathrm{CPB}$; (4) recent treatment with steroids or condition that might require treatment with steroids, excluding steroid administration specifically for CPB; and (5) the use of another investigational drug.

Cardiac surgical procedures were performed at the St. Louis Children's Hospital surgical suite. Additional postoperative care and studies were performed in the pediatric cardiac intensive care unit (CICU). The time points were referenced from the time of admission to the pediatric CICU for both groups. A standardized anesthetic protocol was used throughout the study period. The intraoperative measurements included the aortic crossclamp time and total CPB time. The intraoperative hemodynamic measurements included the mean arterial blood pressure, central venous pressure, right atrial pressure, and pulmonary artery pressure (when available).

The patients were randomized by the research perfusionist using sequentially ordered randomization codes. The randomization codes were generated using a computerized random number generator. The patients in group 1 (treatment group) received standard care with the addition of gNO. After termination of $\mathrm{CPB}$, the $\mathrm{gNO}$ was discontinued. The patients in group 2 (control group) were treated with a strategy identical to that in the treatment group, with the exception that they had not received gNO at any point. The entire care team was unaware of the delivery device and drug delivery. Only the study perfusionist was aware of the randomization and delivery. All equipment and devices were identical.

\section{NO Delivery}

Gas was delivered using the Inovent Transport delivery device (Ikaria, Hampton, NJ), which was calibrated according to the manufacturer's instructions before use. After $\mathrm{CPB}$ circuit set up and priming, the NO injection arm of the Inovent was incorporated into the oxygen delivery tubing. This procedure was accomplished by simply adding reducing connectors from the NO injector to connect the injector to the 0.25 -in oxygenator gas supply tubing. NO sampling was performed by adding a luer lock connector to the gas tubing approximately 4 in. proximal to the oxygenator gas inlet and attaching the sampling line to this connector. The gas supply to the membrane oxygenator was as follows: oxygen/air blender plus carbon dioxide flow meter to the Isoforane vaporizer to the Inovent injector to NO sampling port to in-line gas filter to the membrane oxygenator. Immediately before the start of $\mathrm{CPB}$, the gas tubing was disconnected from the oxygenator, and gas flow was started at 2 to $5 \mathrm{~L} / \mathrm{min}$. Delivery of NO was initiated at $80 \mathrm{ppm}$ until the return sample began to increase. At that point, the delivery of NO was reduced to $20 \mathrm{ppm}$. Once the return sample read $20 \pm 2 \mathrm{ppm}$, the gas flow was turned off, and the tubing was reconnected to the oxygenator. This process ensured that NO was delivered immediately to the oxygenator as soon as the gas flow was initiated with the beginning of $\mathrm{CPB}$.

\section{Performance of CPB}

CPB was performed using established institutional protocols and was not altered during the study period. All patients received $30 \mathrm{mg} / \mathrm{kg}$ of methylprednisolone in the bypass prime volume. In brief, the CPB circuit consisted of 0.25-in. tubing and incorporated a Capiox pediatric arterial filter. A Capiox RX05 hollow fiber oxygenator (Terumo Cardiovascular Systems, Ann Arbor, Mich) with a hard shell venous reservoir used for all cases. The tubing, oxygenator, and venous reservoir were coated with Terumo's $\mathrm{X}$ Coating (Terumo Cardiovascular Systems), a proprietary biocompatible material applied to the blood-contacting surfaces. A hemoconcentrator was used for all cases, both during CPB and afterward, to perform modified ultrafiltration. The prime volume was 400 to $450 \mathrm{~mL}$, depending on the starting reservoir volume. The prime volume consisted of 200 to $300 \mathrm{~mL}$ of Plasma-Lyte A, $100 \mathrm{~mL}$ of $25 \%$ albumin, $1 \mathrm{~g} / \mathrm{kg}$ mannitol, $5000 \mathrm{U}$ of heparin, 400 to $500 \mathrm{mg}$ of calcium gluconate, $30 \mathrm{mg} / \mathrm{kg}$ of Solu-Medrol, 15 to $20 \mathrm{mEq} \mathrm{NaHCO}$, and packed red blood cells. The volume of packed red blood cells varied by patient size and starting hematocrit. Our target hematocrit was $>25 \%$. The activated clotting time and heparin levels were monitored using Medtronic's HMS system (Medtronic, Minneapolis, Minn). For patients with heparin requirements $>6 \mathrm{U} / \mathrm{mL}$, fresh frozen plasma $10 \mathrm{~mL} / \mathrm{kg}$ was administered before $\mathrm{CPB}$ and a repeat heparin dose response was obtained. Our goal was a heparin requirement of $<6$ $\mathrm{U} / \mathrm{mL}$. Ascending aortic and bicaval cannulation was used for all cases. On initiation of CPB, a left ventricular vent was inserted by way of the right pulmonary veins. Blood gases were managed using an alpha-stat strategy. Myocardial protection was accomplished using a cold hyperkalemic solution consisting of $1000 \mathrm{~mL} \mathrm{5 \%}$ dextrose, $27 \mathrm{mEq}$ sodium chloride, $20 \mathrm{mEq}$ potassium chloride, $3 \mathrm{mEq}$ magnesium chloride, and $10 \mathrm{mEq}$ sodium bicarbonate, which was mixed at approximately $4: 1$ with blood from the CPB circuit and delivered into the ascending aorta after placement of the aortic crossclamp. Additionally, topical ice slush was used. The initial cardioplegia dose was 20 to $30 \mathrm{~mL} / \mathrm{kg}$, with additional doses $(50-100 \mathrm{~mL})$ given every 20 to 25 minutes. The initial dose and the subsequent doses varied according to patient size. No differences were found between the 2 groups in any CPB parameters, including the mean arterial blood pressure during $\mathrm{CPB}$, flow rates, fluid balance, and ultrafiltration conduct.

\section{Sample and Data Collection}

Five samples were obtained from each patient immediately before surgery on induction of anesthesia; on admission to the pediatric CICU after surgery; and at 12,24, and 48 hours after surgery. The measurements included methemoglobin, the prothrombin time, partial thromboplastin time, complete blood count, arterial lactate, arterial blood gas, serum electrolytes, creatinine, cardiac troponin $\mathrm{I}(\mathrm{cTnI})$, B-type natriuretic peptide (BNP), interleukin [IL]-6, IL-8, and tumor necrosis factor- $\alpha$. Measurements of the clinical parameters were collected throughout the study period and included fluid balance, urine output, and diuretic administration. Additionally, the ventilator settings, length of CICU and hospital stay were recorded. Patients were followed up until discharge from the institution.

\section{Sample Processing}

The cytokine measurements (IL-6, IL-8, tumor necrosis factor- $\alpha$ ) were determined using commercially available assays (IBT Laboratories, Lenexa, Kan). The serum levels of cTnI and BNP were determined using commercially available assays (Siemens Healthcare Diagnostics, Washington, DC, and Bayer Diagnostics, Leverkusen, Germany, respectively). 
TABLE 1. Comparison of patient demographics and clinical data

\begin{tabular}{lccc}
\hline \multicolumn{1}{c}{ Variable } & $\begin{array}{c}\text { Gaseous nitric } \\
\text { oxide group }\end{array}$ & Placebo group & $\boldsymbol{P}$ value \\
\hline Gender (n) & & & NS \\
$\quad$ Male & 7 & 4 & \\
$\quad$ Female & 1 & 4 & \\
Age (d) & $191 \pm 112$ & $216 \pm 114$ & NS \\
CPB time (min) & $118 \pm 31$ & $128 \pm 36$ & NS \\
Crossclamp time (min) & $60 \pm 10$ & $67 \pm 9$ & NS \\
Ventilator duration (h) & $8.4 \pm 7.6$ & $16.3 \pm 6.5$ & $<.05$ \\
CICU LOS (h) & $53.8 \pm 19.7$ & $79.4 \pm 37.7$ & $<.05$ \\
Hospital LOS (d) & $5.63 \pm 2.5$ & $5.13 \pm 1.2$ & NS \\
\hline Dit
\end{tabular}

Data presented as $\mathrm{n}$ or mean \pm standard deviation. $C P B$, Cardiopulmonary bypass; $C I C U$, cardiac intensive care unit; $L O S$, length of stay; NS, not significant.

\section{Statistical Analysis}

All statistical analyses were conducted using Statistical Analysis System, version 9.1 (SAS Institute, Cary, NC). The continuous demographic and clinical variables listed in Table 1 were compared between the gNO and placebo groups using the 2-independent sample $t$ test or the Wilcoxon 2-Sample test, whichever was appropriate. Gender was compared between the groups using Fisher's exact test. The laboratory variables listed in Table 2, including cTnI and BNP, were compared between the NO and placebo groups using the 2-independent sample $t$ test or Wilcoxon 2-sample test, as appropriate.

\section{RESULTS}

\section{Patient Characteristics}

A total of 25 patients were eligible for participation according to the inclusion and exclusion criteria. Of the $25 \mathrm{pa}-$ tients, 16 consented and were enrolled in the present study. The parents or guardians of 8 patients did not provide consent. One patient was disqualified after consent and randomization owing to intraoperative findings of a lesion inconsistent with the preoperative diagnosis and a change in the operative plan. The patient characteristics are listed in Table 1. No differences were found in age, CPB time, crossclamp time, or surgical approach and technique. The same 2 surgeons performed all the operations during the study period. No patients in the study population underwent ventriculotomy, and none were left with pulmonary insufficiency. No differences were found in the operative start times and time of admission to the CICU. There was a preponderance of males in the present study, consistent with the overall prevalence of congenital heart defects. No child received additional gNO outside the study protocol. No patients died in the present study.

The group receiving gNO had a significantly shorter duration of mechanical ventilation support. The patients were ventilated for $8.4 \pm 7.6$ hours compared with $16.3 \pm 6.5$ hours $(P<.05)$, a nearly $50 \%$ reduction (Figure $1, A$ ). The gNO group had a $32 \%$ reduction in the length of stay in the pediatric CICU $(53.8 \pm 19.7$ vs $79.4 \pm 37.7$ hours, $P<.05$; Figure $1, B)$. No differences were found in the overall hospital length of stay between the 2 groups (Table 1 ).
TABLE 2. Comparison of laboratory and clinical results between study and placebo groups

\begin{tabular}{|c|c|c|c|}
\hline Variable & Nitric oxide & Placebo & $\begin{array}{c}P \\
\text { value }\end{array}$ \\
\hline $\begin{array}{l}\text { Postoperative fluid balance } \\
\text { (total } \mathrm{mL} \text { within } 48 \mathrm{~h} \text { ) }\end{array}$ & $187 \pm 122$ & $317 \pm 271$ & NS \\
\hline Lasix (total mL within $48 \mathrm{~h}$ ) & $1.63 \pm 0.9$ & $3.25 \pm 1.0$ & $<.05$ \\
\hline Chlorothiazide (mg/kg total $48 \mathrm{~h}$ ) & 0 & $6.3 \pm 7.4$ & $<.05$ \\
\hline Greatest methemoglobin $(\mathrm{g} / \mathrm{dL})$ & $1.3 \pm 0.5$ & $1.3 \pm 0.3$ & NS \\
\hline Hemoglobin $(\mathrm{g} / \mathrm{dL})$ & $11.8 \pm 1.7$ & $9.8 \pm 0.9$ & $<.05$ \\
\hline $\begin{array}{l}\text { Chest tube output (total } \mathrm{mL} \\
\text { within } 48 \mathrm{~h} \text { ) }\end{array}$ & $260 \pm 44$ & $310 \pm 131$ & NS \\
\hline $\begin{array}{l}\text { PRBC transfusion (total mL } \\
\text { within } 48 \mathrm{~h} \text { ) }\end{array}$ & $45 \pm 43$ & $47 \pm 75$ & NS \\
\hline $\begin{array}{l}\text { Platelet transfusion (total } \mathrm{mL} \\
\text { within } 48 \mathrm{~h} \text { ) }\end{array}$ & 0 & 0 & NS \\
\hline $\begin{array}{l}\text { FFP transfusion (total mL } \\
\text { within } 48 \mathrm{~h} \text { ) }\end{array}$ & $6 \pm 18$ & $16 \pm 30$ & NS \\
\hline \multicolumn{4}{|l|}{$\mathrm{IL}-6(\mathrm{ng} / \mathrm{mL})$} \\
\hline Preoperative & $3.8 \pm 3.5$ & $3.4 \pm 2.5$ & NS \\
\hline $0 \mathrm{~h}$ & $90.9 \pm 44.6$ & $78.3 \pm 45.7$ & NS \\
\hline $12 \mathrm{~h}$ & $51.5 \pm 38.7$ & $73.3 \pm 67.0$ & NS \\
\hline $24 \mathrm{~h}$ & $64.2 \pm 28.4$ & $80.7 \pm 82.1$ & NS \\
\hline $48 \mathrm{~h}$ & $31.2 \pm 30.6$ & $39.4 \pm 48.9$ & NS \\
\hline \multicolumn{4}{|l|}{ IL-8 (ng/mL) } \\
\hline Preoperative & $60.9 \pm 28.2$ & $39.8 \pm 39.0$ & NS \\
\hline $0 \mathrm{~h}$ & $189.8 \pm 104.1$ & $248.9 \pm 191.7$ & NS \\
\hline $12 \mathrm{~h}$ & $144 \pm 133.4$ & $85.9 \pm 59.9$ & NS \\
\hline $24 \mathrm{~h}$ & $101.5 \pm 62.7$ & $139.2 \pm 162.1$ & NS \\
\hline $48 \mathrm{~h}$ & $134.2 \pm 107.0$ & $60.4 \pm 33.7$ & NS \\
\hline \multicolumn{4}{|l|}{ Tumor necrosis factor- $\alpha(\mathrm{ng} / \mathrm{mL})$} \\
\hline Preoperative & $2.9 \pm 0.8$ & $3.2 \pm 1.1$ & NS \\
\hline $0 \mathrm{~h}$ & $3.2 \pm 1.5$ & $4.1 \pm 1.6$ & NS \\
\hline $12 \mathrm{~h}$ & $1.7 \pm 0.07$ & $1.9 \pm 1.1$ & NS \\
\hline $24 \mathrm{~h}$ & $1.7 \pm 1.3$ & $3.2 \pm 2.9$ & NS \\
\hline $48 \mathrm{~h}$ & $2.8 \pm 0.09$ & $2.1 \pm 1.2$ & NS \\
\hline \multicolumn{4}{|l|}{ Lactate (mmol/L) } \\
\hline Preoperative & $0.9 \pm 0.2$ & $0.5 \pm 0.1$ & NS \\
\hline $0 \mathrm{~h}$ & $1.9 \pm 0.6$ & $1.9 \pm 1.0$ & NS \\
\hline $12 \mathrm{~h}$ & $1.5 \pm 0.4$ & $1.5 \pm 0.5$ & NS \\
\hline $24 \mathrm{~h}$ & $1.4 \pm 0.5$ & $1.4 \pm 0.4$ & NS \\
\hline $48 \mathrm{~h}$ & $1.1 \pm 0.2$ & $1.1 \pm 0.2$ & NS \\
\hline \multicolumn{4}{|l|}{ cTnI (ng/mL) } \\
\hline Preoperative & $0.07 \pm 0.07$ & $0.06 \pm 0.1$ & NS \\
\hline $0 \mathrm{~h}$ & $50.6 \pm 37.8$ & $54.1 \pm 15.5$ & NS \\
\hline $12 \mathrm{~h}$ & $11.7 \pm 3.2$ & $15.9 \pm 3.5$ & $<.05$ \\
\hline $24 \mathrm{~h}$ & $8.9 \pm 2.6$ & $12.5 \pm 2.7$ & $<.05$ \\
\hline $48 \mathrm{~h}$ & $4.8 \pm 1.6$ & $7.6 \pm 2.0$ & $<.05$ \\
\hline \multicolumn{4}{|l|}{$\mathrm{BNP}(\mathrm{pg} / \mathrm{dL})$} \\
\hline Preoperative & $24 \pm 22$ & $100 \pm 195$ & NS \\
\hline $0 \mathrm{~h}$ & $43 \pm 34$ & $94 \pm 100$ & NS \\
\hline $12 \mathrm{~h}$ & $494 \pm 222$ & $812 \pm 300$ & $<.05$ \\
\hline $24 \mathrm{~h}$ & $425 \pm 154$ & $938 \pm 511$ & $<.05$ \\
\hline $48 \mathrm{~h}$ & $558 \pm 535$ & $1298 \pm 827$ & NS \\
\hline
\end{tabular}

PRBC, Packed red blood cell; $F F$, fresh frozen plasma; $I L$, interleukin; $c T n I$, cardiac troponin I; $B N P$, B-type natriuretic peptide; $N S$, not significant. 

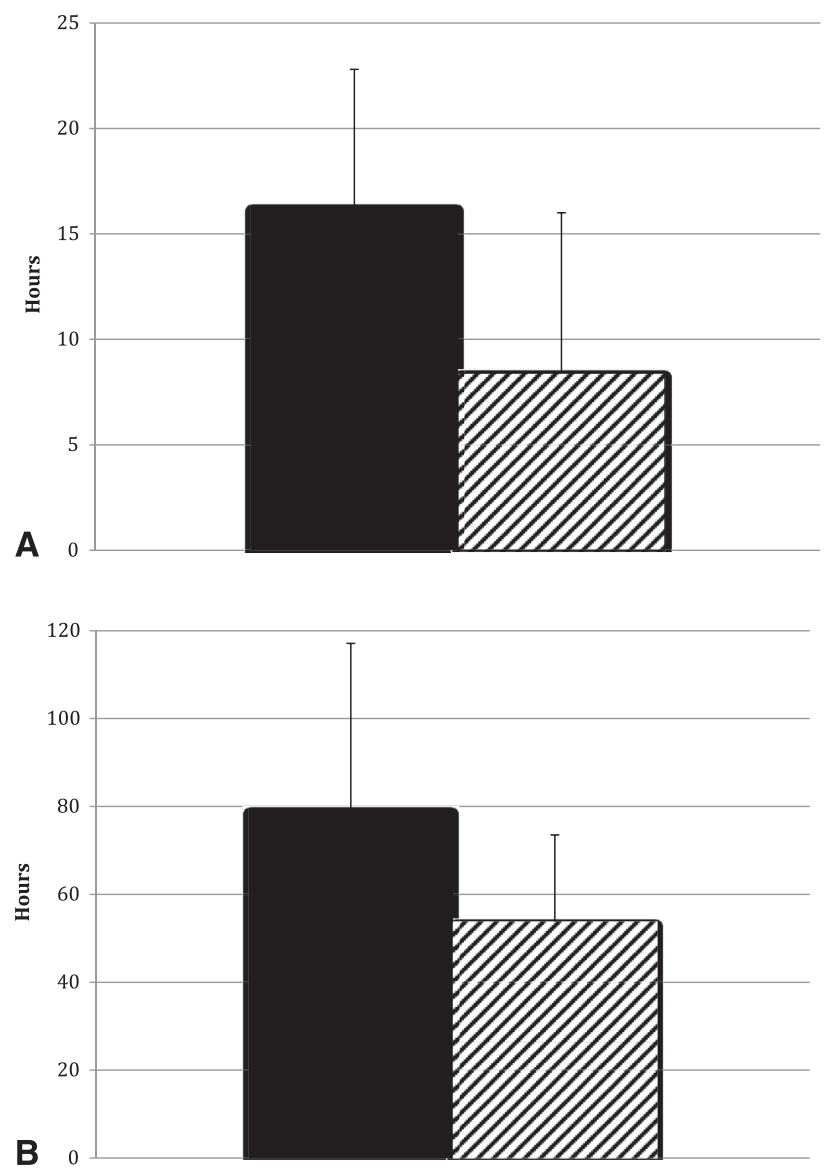

FIGURE 1. A, Comparison of ventilator hours. B, Comparison of intensive care unit length of stay. $P<.05$ for both graphs. Solid bar, placebo group; hatched bar, gaseous nitric oxide group.

The delivery of gNO appears to have a cardioprotective effect, as indicated by the cTnI and BNP values (Table 2). The gNO group had lower cTnI values at 12,24 , and 48 hours $(P<.05$; Figure $2, A)$. Additionally, the gNO group had lower BNP measurements at 12 and 24 hours $(P<.05$; Figure $2, B)$.

Overall, the postoperative fluid balance in the first 48 hours showed a trend toward an improved balance in the gNO group but failed to achieve significance $(+187 \mathrm{~mL}$ in the gNO group vs $+317 \mathrm{~mL}$ in the placebo group). This finding was present even though the treatment group received significantly less diuretic during the same period $(1.6 \pm 0.9 \mathrm{mg} / \mathrm{kg}$ vs $4.0 \pm 1.0 \mathrm{mg} / \mathrm{kg}$ intravenous furosemide, $P<.05$ ). Furthermore, no patients in the $\mathrm{gNO}$ group received chlorothiazide; however, patients in the placebo group received a mean total dose of $6.3 \pm 7.4 \mathrm{mg} / \mathrm{kg}$ in the first 48 hours postoperatively $(P<.05$; Table 2$)$. No differences were found in the mean serum creatinine or blood urea nitrogen between the 2 groups (data not shown).

The patients who received gNO during $\mathrm{CPB}$ had a greater mean hemoglobin at 48 hours $(11.8 \pm 1.7$ vs $9.8 \pm 0.9 \mathrm{~g} / \mathrm{dL}$,
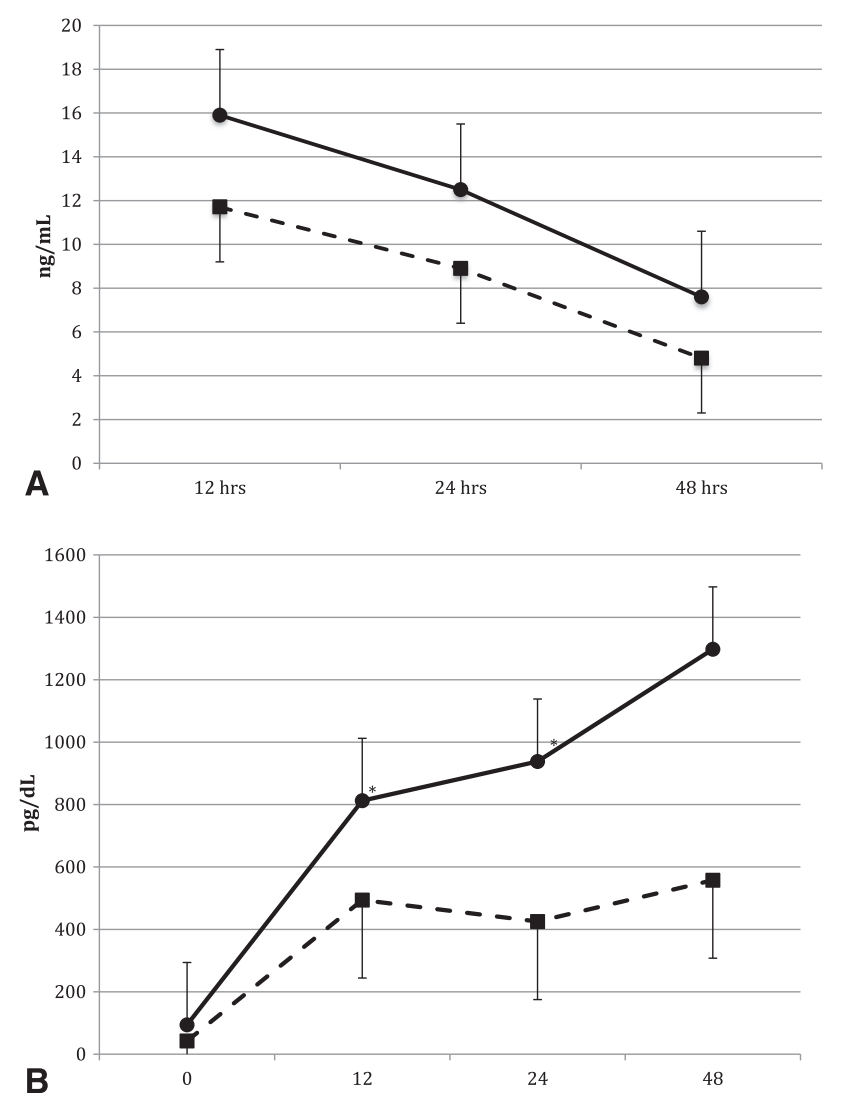

FIGURE 2. A, Comparison of cardiac troponin values. $P<.05$ at all points. B, Comparison of B-type natriuretic peptide measurements. Solid line, placebo; hatched line, gaseous nitric oxide group. $* P<.05$ at 12- and 24-hour points.

$P<.05)$ despite no differences in chest tube output, packed red blood cell transfusion, platelet counts or transfusion, fresh frozen plasma transfusion, or prothrombin time or partial thromboplastin time in the first 48 hours after surgery (Table 2).

No differences were found between the 2 groups in the inflammatory response, as assessed by serum IL- 6 , IL-8, or tumor necrosis factor- $\alpha$ levels. Additionally, no differences in arterial blood gas measurements or arterial lactate measurements were found between the 2 groups at any measurement point (Table 2). Finally, no differences were seen in any other hemodynamic variable measured, including the systolic and diastolic blood pressure, mean arterial blood pressure, inotropic score, heart rate, fluid administration, or central venous pressure measurements throughout the study period.

\section{DISCUSSION}

In the present study, we evaluated the effect of the delivery of gNO to the membrane oxygenator of the CPB circuit on the postoperative outcome measures in children undergoing cardiac surgery for congenital heart disease. Children who received gNO during CPB had an improved postoperative course, which was demonstrated by significantly reduced 
myocardial injury and a shortened duration of mechanical ventilation and length of stay in the pediatric CICU.

These findings have the potential for significant clinical effect. In the United States alone, approximately 400,000 cardiac surgical operations are performed annually, of which 10,000 are performed in children. In nearly all cases, these procedures induce ischemia/reperfusion injury and generate a systemic inflammatory response syndrome. As a result, organ function is impaired, leading to an increase in vascular permeability, fluid retention, and significant morbidity and potential mortality. Children appear to be particularly susceptible to developing multisystem organ failure as a result of these processes. ${ }^{7}$

Ischemia/reperfusion injury and systemic inflammatory response syndrome are linked. Myocardial and pulmonary ischemia/reperfusion injury is, in large part, an inflammatory phenomenon. After a period of ischemia, reperfusion stimulates the release of additional pro-inflammatory mediators, in particular, reactive oxygen species and cytokines, by parenchymal, endothelial, platelet, and inflammatory cells, contributing to elevated serum levels of inflammatory mediators. Cell death results from coagulation necrosis and inflammatory mediator-induced apoptosis. Central to the pathophysiology of reperfusion injury is endothelial damage, resulting in impairment of the NO-cyclic guanosine monophosphate signaling cascade and endothelialdependent vasodilation. ${ }^{8}$ Reperfusion injury is modulated by supplemental gNO. This "local" inflammation contributes to the systemic inflammatory response syndrome by spilling over into the systemic circulation and in so doing "contributes" to the systemic inflammatory response. We believe that glucocorticoids administered before either stimulus (inflammation or ischemia/reperfusion) attenuates the inflammatory response. We theorized that the study results could potentially be more dramatic if the immune system had not been primed at all, in particular, when studying the markers of reperfusion injury.

NO appears to be a key link between ischemia/reperfusion injury and the rate of tissue repair. ${ }^{9}$ Alterations in NO generation appear to underpin the interrelationship of endothelial function and inflammation. ${ }^{6}$ Although NO has been used for pulmonary hypertension for well over a decade, its role in tissue injury, apoptosis, and inflammation was the focus of the present study and of other investigations. ${ }^{10} \mathrm{NO}$ might play several protective roles in myocardial reperfusion injury. ${ }^{11} \mathrm{NO}$ is an important regulator of apoptosis, capable of both inducing and preventing apoptosis. ${ }^{12} \mathrm{NO}$ has been shown to inhibit platelet adhesion and aggregation ${ }^{13}$ and is able to block monocyte adherence and migration. ${ }^{14}$ Furthermore, NO is an inhibitor of leukocyte activation, preventing neutrophil-endothelium adhesion and the generation of oxygen free radicals. ${ }^{15}$

Given each of these factors, NO serves as a potential therapeutic target. Hataishi and colleagues ${ }^{5}$ demonstrated that breathing NO markedly decreases the myocardial infarction size and improves left ventricular function after ischemia and reperfusion. Exogenous NO is a potent cardioprotective agent that modulates neutrophil-mediated damage. ${ }^{16}$ Additionally, gNO appears to serve as a cardioprotective agent in an animal model of cardiac arrest and cardiopulmonary resuscitation. ${ }^{17}$ Finally, although none of these investigations specifically involved arterial delivery of gNO, such as we used in our study, the overall theoretical basis for this delivery has been supported by several reports. ${ }^{18-20}$

The ischemia/reperfusion injury that occurs after cardioplegic arrest leads to myocardial injury and impaired function. It is this specific organ injury that appears to be most affected by the addition of $\mathrm{gNO}$ in our results. The mechanisms involved in this process could include reperfusion-induced inflammation and apoptosis. ${ }^{21}$ Because myocardial apoptosis is a part of normal fetal and postnatal maturation, the immature myocardium of the infant might have an increased vulnerability or susceptibility to apoptosis-related processes after surgery, contributing to postoperative ventricular dysfunction. ${ }^{12}$

Our premise was that NO added to the circuit would have effects distal to the entry site. This concept is inconsistent with the current dogma regarding $\mathrm{NO}$ metabolism. However, increasing evidence has shown that NO, or NO donors, given to patients with decreased NO bioavailability results in decreased vascular resistance, increased blood flow, and decreased inflammation, and, thereby, decreased tissue damage. $^{22}$ This finding has been modeled in disease states involving hemolysis, such as sickle cell disease. Specifically, Reiter and colleagues ${ }^{23}$ have demonstrated that cell-free hemoglobin limits NO bioavailability in patients with sickle cell disease. Decompartmentalized hemoglobin scavenges endogenously generated and exogenously delivered NO. A similar phenomenon might also occur with crush injuries, during $\mathrm{CPB}$, and with transfusion reactions. ${ }^{24}$ The hemolysis associated with cardiovascular surgery and NO bioavailability was recently reviewed by Vermeulen Windsant and colleagues. ${ }^{25}$ An acute scavenging of NO by oxyhemoglobin liberated by hemolysis during CPB, without regard to vascular histologic limitations, might produce the required vasoconstriction, platelet activation, leukocyte-endothelial cell adhesion, and oxygen free radical generation necessary to explain the clinical phenomenon associated with CPB and myocardial reperfusion injury. This could be compounded by the lack of bioavailability of NO in stored and transfused blood during the operative period. ${ }^{26}$ Although this mechanism might have affected our results, we did not find direct evidence of hemolysis in our population.

Our findings of the changes in fluid balance, BNP, and diuretic usage imply either an improved hemodynamic profile or a renal effect of gNO delivery. Investigators have postulated a role of $\mathrm{NO}$ on renal protection after ischemia and reperfusion. ${ }^{27}$ Animal models have demonstrated that CPB-induced ischemia/reperfusion and inflammation result 
in glomerular and renal tubular damage associated with endothelial cell injury and activation and leukocyte sequestration and reduced glomerular filtration rates and creatinine clearance. ${ }^{28}$ Additionally, models of renal ischemia/reperfusion injury have clearly demonstrated the role of inflammation in producing tubular injury and dysfunction, findings much more dramatic than those reported for CPB-induced inflammation alone. ${ }^{29}$

Children who received gNO had a greater mean hemoglobin throughout the initial postoperative period, despite the lack of increased blood product usage. This was a surprising finding, and we do not have a clear causative explanation because we did not find evidence of hemolysis. Although it might have been related to the fluid balance, the role of $\mathrm{gNO}$ in this process has been supported by previous investigations. Multiple investigators have demonstrated the NO effects on platelet function, adhesion and aggregation in bypass and hemorrhagic shock. ${ }^{30}$ However, we did not find a change in coagulation measurements or bleeding in the study group, thereby mitigating any potential interpretation of the effect of $\mathrm{NO}$ on coagulation.

Our results lend support to the speculation of a mechanistic construct. CPB with cardioplegic arrest leads to ischemia and reperfusion injury of the myocardium, endothelial dysfunction, and changes in vasodilatory response, which are exacerbated by the imbalance of NO bioavailability associated with hemolysis and stored blood transfusion. Finally, renal injury occurs through both inflammation and hemodynamic compromise, leading to a decreased glomerular filtration rate and fluid imbalance.

Our study had important limitations. First, our study was a pilot investigation and, therefore, had limited subjects. Additionally, we chose to investigate a single lesion, tetralogy of Fallot. The effect of this unique anatomy, specifically with regard to right ventricular structure and function, is unknown. All patients in the present study received systemic steroids. Finally, we did not have access to biopsy specimens from the myocardium or kidneys, which would have aided in clarifying the proposed mechanisms of action. Despite these limitations, our results have demonstrated a robust biochemical and clinically meaningful outcome.

In conclusion, we evaluated the effect of gNO delivery to the membrane oxygenator of the CPB circuit on the postoperative outcome measures in pediatric patients with congenital heart disease. The children who received gNO during $\mathrm{CPB}$ had an improved postoperative course, as demonstrated by a shorter length of stay in the pediatric CICU, a shorter duration of mechanical ventilation requirement, and improved indexes of myocardial injury and function.

\section{References}

1. Domanski MJ, Mahaffey K, Hasselblad V, Brener SJ, Smith PK, Hillis G, et al. Association of myocardial enzyme elevation and survival following coronary artery bypass graft surgery. JAMA. 2011;305:585-91.
2. Zahler S, Massoudy P, Hartl H, Hahnel C, Meisner H, Becker BF. Acute cardiac inflammatory responses to postischemic reperfusion during cardiopulmonary bypass. Cardiovasc Res. 1999;41:722-30.

3. Boyle EM Jr, Pohlman TH, Johnson MC, Verrier ED. Endothelial cell injury in cardiovascular surgery: the systemic inflammatory response. Ann Thorac Surg. 1997;63:277-84

4. Schechter AN, Gladwin MT. Hemoglobin and the paracrine and endocrine functions of nitric oxide. N Engl J Med. 2003;348:1483-5.

5. Hataishi R, Rodrigues AC, Neilan TG, Morgan JG, Buys E, Shiva S, et al. Inhaled nitric oxide decreases infarction size and improves left ventricular function in a murine model of myocardial ischemia-reperfusion injury. Am J Physiol. 2006;291:H379-84.

6. Chello M, Mastroroberto P, Perticone F, Celi V, Colonna A. Nitric oxide modulation of neutrophil-endothelium interaction: difference between arterial and venous coronary bypass grafts. J Am Coll Cardiol. 1998;31:823-6.

7. Duval EL, Kavelaars A, Veenhuizen L, van Vught AJ, van de Wal HJ, Heijnen CJ. Pro- and anti-inflammatory cytokine patterns during and after cardiac surgery in young children. Eur J Pediatr. 1999;158:387-93.

8. Cooper WA, Duarte IG, Thourani VH, Nakamura M, Wang NP, Brown WM III, et al. Hypothermic circulatory arrest causes multisystem vascular endothelial dysfunction and apoptosis. Ann Thorac Surg. 2000;69:696-703.

9. Pabla R, Curtis MJ. Effect of endogenous nitric oxide on cardiac systolic and diastolic function during ischemia and reperfusion in the rat isolated perfused heart. J Mol Cell Cardiol. 1996;28:2111-21.

10. Kubes P, Suzuki M, Granger DN. Nitric oxide: an endogenous modulator of leukocyte adhesion. Proc Natl Acad Sci U S A. 1991;88:4651-5.

11. Gianetti J, Del Sarto P, Bevilacqua S, Vassalle C, De Filippis R, Kacila M, et al Supplemental nitric oxide and its effect on myocardial injury and function in patients undergoing cardiac surgery with extracorporeal circulation. J Thorac Cardiovasc Surg. 2004;127:44-50.

12. Uchiyama T, Otani H, Okada T, Ninomiya H, Kido M, Imamura H, et al. Nitric oxide induces caspase-dependent apoptosis and necrosis in neonatal rat cardiomyocytes. J Mol Cell Cardiol. 2002;34:1049-61.

13. Sawicki G, Salas E, Murat J, Miszta-Lane H, Radomski MW. Release of gelatinase a during platelet activation mediates aggregation. Nature. 1997;386: 616-9.

14. Comini L, Bachetti T, Agnoletti L, Gaia G, Curello S, Milanesi B, et al. Induction of functional inducible nitric oxide synthase in monocytes of patients with congestive heart failure: link with tumour necrosis factor-alpha. Eur Heart J. 1999; 20:1503-13.

15. Van Dervort AL, Yan L, Madara PJ, Cobb JP, Wesley RA, Corriveau CC, et al Nitric oxide regulates endotoxin-induced TNF-alpha production by human neutrophils. J Immunol. 1994;152:4102-9.

16. Ambrosio G, Tritto I. Reperfusion injury: experimental evidence and clinical implications. Am Heart J. 1999;138:S69-75.

17. Minamishima S, Kida K, Tokuda K, Wang H, Sips PY, Kosugi S, et al. Inhaled nitric oxide improves outcomes after successful cardiopulmonary resuscitation in mice. Circulation. 2011;124:1645-53.

18. Jones SP, Bolli R. The ubiquitous role of nitric oxide in cardioprotection. $J \mathrm{Mol}$ Cell Cardiol. 2006;40:16-23.

19. Schulz R, Kelm M, Heusch G. Nitric oxide in myocardial ischemia/reperfusion injury. Cardiovasc Res. 2004;61:402-13.

20. Jones SP, Girod WG, Palazzo AJ, Granger DN, Grisham MB, Jourd'Heuil D, et al. Myocardial ischemia-reperfusion injury is exacerbated in absence of endothelial cell nitric oxide synthase. Am J Physiol. 1999;276: H1567-73.

21. Duranski MR, Greer JJ, Dejam A, Jaganmohan S, Hogg N, Langston W, et al. Cytoprotective effects of nitrite during in vivo ischemia-reperfusion of the heart and liver. J Clin Invest. 2005;115:1232-40.

22. Lundberg JO, Weitzberg E, Gladwin MT. The nitrate-nitrite-nitric oxide pathway in physiology and therapeutics. Nat Rev Drug Discov. 2008;7: 156-67.

23. Reiter CD, Wang X, Tanus-Santos JE, Hogg N, Cannon RO III, Schechter AN, et al. Cell-free hemoglobin limits nitric oxide bioavailability in sickle-cell disease. Nat Med. 2002;8:1383-9.

24. Cheung AT, Cruz-Shiavone GE, Meng QC, Pochettino A, Augoustides JA, Bavaria JE, et al. Cardiopulmonary bypass, hemolysis, and nitroprussideinduced cyanide production. Anesth Analg. 2007;105:29-33.

25. Vermeulen Windsant IC, Hanssen SJ, Buurman WA, Jacobs MJ. Cardiovascular surgery and organ damage: time to reconsider the role of hemolysis. $J$ Thorac Cardiovasc Surg. 2011;142:1-11. 
26. Donadee C, Raat NJ, Kanias T, Tejero J, Lee JS, Kelley EE, et al. Nitric oxide scavenging by red blood cell microparticles and cell-free hemoglobin as a mechanism for the red cell storage lesion. Circulation. 2011;124: 465-76.

27. Versteilen AM, Blaauw N, Di Maggio F, Groeneveld AB, Sipkema P, Musters RJ, et al. Rho-kinase inhibition reduces early microvascular leukocyte accumulation in the rat kidney following ischemia-reperfusion injury: roles of nitric oxide and blood flow. Nephron Exp Nephrol. 2011;118: e79-86.
28. Murphy GJ, Lin H, Coward RJ, Toth T, Holmes R, Hall D, et al. An initial evaluation of post-cardiopulmonary bypass acute kidney injury in swine. Eur J Cardiothorac Surg. 2009;36:849-55.

29. Klausner JM, Paterson IS, Goldman G, Kobzik L, Rodzen C, Lawrence R, et al. Postischemic renal injury is mediated by neutrophils and leukotrienes. Am J Physiol. 1989;256:F794-802.

30. Mellgren K, Friberg LG, Mellgren G, Hedner T, Wennmalm A, Wadenvik H. Nitric oxide in the oxygenator sweep gas reduces platelet activation during experimental perfusion. Ann Thorac Surg. 1996;61:1194-8.

Access to The Journal of Thoracic and Cardiovascular Surgery Online is reserved for print subscribers!

Full-text access to The Journal of Thoracic and Cardiovascular Surgery Online is available for all print subscribers. To activate your individual online subscription, please visit The Journal of Thoracic and Cardiovascular Surgery Online, point your browser to http://www.mosby.com/jtcvs, follow the prompts to activate your online access, and follow the instructions. To activate your account, you will need your subscriber account number, which you can find on your mailing label (note: the number of digits in your subscriber account number varies from 6 to 10). See the example below in which the subscriber account number has been circled:

\section{Sample mailing label}

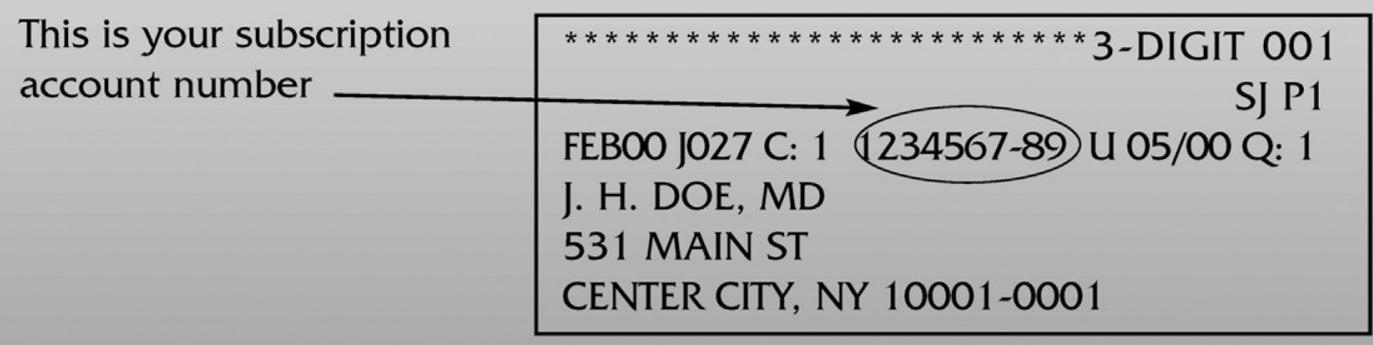

Personal subscriptions to The Journal of Thoracic and Cardiovascular Surgery Online are for individual use only and may not be transferred. Use of The Journal of Thoracic and Cardiovascular Surgery Online is subject to agreement to the terms and conditions as indicated online. 